\title{
Hlf, a novel hepatic bZIP protein, shows altered DNA-binding properties following fusion to E2A in $t(17 ; 19)$ acute lymphoblastic leukemia
}

\author{
Stephen P. Hunger, Kazuma Ohyashiki, ${ }^{1}$ Keisuke Toyama, ${ }^{1}$ and Michael L. Cleary ${ }^{2}$ \\ Laboratory of Experimental Oncology, Department of Pathology, Stanford University School of Medicine, \\ Stanford, California 94305 USA; $^{\text {I}}$ First Department of Internal Medicine, Tokyo Medical College, 6-7-1 Nishishinjuku, \\ Shinjuku-ku, Tokyo 160, Japan
}

Oncogenic conversion of transcription factors by chromosomal translocations is implicated in leukemogenesis. We report that the $t(17 ; 19)$ in acute lymphoblastic leukemia produces a chimeric transcription factor consisting of the amino-terminal portion of HLH proteins E12/E47 (products of the E2A gene) fused to the basic DNA-binding and leucine zipper dimerization motifs of a novel hepatic protein called hepatic leukemia factor (HIf). Hlf, which is not normally transcribed in lymphoid cells, belongs to the recently described PAR subfamily of basic leucine zipper (bZIP) proteins, which also includes Dbp and Tef/Vbp. Wild-type Hlf is able to bind DNA specifically as a homodimer or as a heterodimer with other PAR factors. Structural alterations of the E2a-Hlf fusion protein markedly impair its ability to bind DNA as a homodimer compared with wild-type Hlf. However, E2a-Hlf can bind DNA as a heterodimer with other PAR proteins, suggesting a novel mechanism for leukemogenic conversion of a bZIP transcription factor.

[Key Words: Chromosomal translocation; transcription factor; bZIP protein; HLH protein; chimeric protein; oncogene]

Received May 22, 1992; revised version accepted July 6, 1992.

The largest group of proto-oncogenes identified to date codes for proteins implicated in regulation of transcription and shares with known transcription factors common structural motifs that mediate cognate interactions with DNA or other components of the transcription complex (Cleary 1991). Molecular studies have suggested several general mechanisms whereby transcriptional proteins may be converted to oncogenic factors in leukemia. One mechanism results in dysregulated expression of wild-type proteins following translocation to a transcriptionally dominant locus such as the immunoglobulin or T-cell receptor (TCR) genes. Dominant transforming properties may also result from protein structural changes in the form of truncations or protein fusions. In acute leukemias, chimeric transcription factors such as E2a-Pbxl and Pml-Rara have been described in $\mathrm{t}(1 ; 19)$-carrying pre-B cell acute lymphoblastic leukemia (ALL) and $t(15 ; 17)$ acute promyelocytic leukemia, respectively (Mellentin et al. 1989; Kamps et al. 1990; Nourse et al. 1990; Cleary 1991; de Thé et al. 1991; Kakizuka et al. 1991; Pandolfi et al. 1991). Structural features of $\mathrm{E} 2 \mathrm{a}-\mathrm{Pbxl}$ fusion proteins suggest that transcrip-

${ }^{2}$ Corresponding authors. tional activation domains may be oncogenic depending on their specific protein contexts. E2a-Pbxl chimeras consist of the DNA-binding homeo domain of $\mathrm{Pbx} 1$ fused to a portion of helix-loop-helix (HLH) proteins E12/E47, which includes a domain with trans-activation properties (Henthorn et al. 1990). Consistent fusion of E2a and Pbx1 has been observed between different pre-B cell $t(1 ; 19)$ leukemias, suggesting that collaboration of specific motifs in each protein determines leukemogenic properties of the chimera (Mellentin et al. 1990; Hunger et al. 1991; Privitera et al. 1992). E2a-Pbxl proteins transform NIH-3T3 cells (Kamps et al. 1991), but mutagenesis studies have not yet established which portions of the chimera are required. Wild-type $\mathrm{Pbxl}$ is not normally expressed in lymphoid cells (Kamps et al. 1990; Nourse et al. 1990; Monica et al. 1991), raising the possibility that $\mathrm{E} 2 \mathrm{a}-\mathrm{Pbxl}$ deregulates target genes normally regulated by $\mathrm{Pbx} 1$ in nonlymphoid cells or genes regulated by highly homologous proteins such as $\mathrm{Pbx} 2$ or Pbx3 in pre-B cells (Monica et al. 1991). These models presuppose that the DNA-binding characteristics of E2a$\mathrm{Pbxl}$ recapitulate those of wild-type $\mathrm{Pbxl}$, an assumption that has not yet been tested experimentally.

To further characterize the role of E2a in leukemogenesis and to establish the spectrum of transcriptional pro- 
teins that may be oncogenically activated by protein fusion, we have investigated potential variant translocations involving E2a in acute leukemias. A newly recognized nonrandom translocation involving the general chromosome 19 region of $E 2 A$, the $\mathrm{t}(17 ; 19)(\mathrm{q} 21-$ q22;pl3), has been described recently in childhood ALL (Raimondi et al. 1991) but molecular studies have provided conflicting results as to the involvement of the E2A gene (Inaba et al. 1991; Ohyashiki et al. 1991; Yamada et al. 1991). In the current study, we demonstrate that the $t(17 ; 19)$ results in fusion of the $E 2 A$ gene to the gene for a novel basic leucine zipper (bZIP) protein lhepatic leukemia factor $(\mathrm{Hlf})]$ resulting in expression of a chimeric transciprtion factor. The $t(17 ; 19)$ fusion protein shows several unique structural and functional features that distinguish it from previously described translocated proteins in ALL. These features are responsible for a marked difference in the DNA-binding properties of the E2a-Hlf fusion protein when compared with wildtype Hlf. These data suggest a novel mechanism for oncogenic conversion of a bZIP protein and may have significant consequences with respect to target genes affected by a chimeric HLH-bZIP transcription factor.

\section{Results \\ Cloning of E2A fusion cDNAs from the HAL-01 cell line}

To assess whether $t(17 ; 19)$ breakpoints involve the $E 2 A$ gene on chromosome 19, Southern blots were performed on the HAL-01 cell line, which was established previously from a patient with $t(17 ; 19)$ ALL /Ohyashiki et al.
1991). Hybridization with a probe that detected rearrangements in all cases of $t(1 ; 19)$ ALL (Mellentin et al. $1989,1990)$ showed that HAL-01 DNA contained E2A gene rearrangements (Fig. 1A), indicating that the $t(17 ; 19)$ breakpoint was located in the $E 2 A$ gene similar to previously reported $t(1 ; 19)$ breakpoints.

Northern blot analyses showed aberrant-sized E2A transcripts $(\sim 4.1$ and $4.3 \mathrm{~kb})$ in HAL-01 in addition to the expected wild-type $E 2 A$ transcripts of 3 and $4.4 \mathrm{~kb}$ (Fig. 1A). E2A homologous cDNAs were isolated from a HAL01 cDNA library by use of a different screening procedure (see Materials and methods) that selected for potential fusion cDNAs containing 5' E2A sequences. Nucleotide sequence analyses indicated that all 10 clones contained 5 ' portions of E2A up to nucleotide 1519 (Nourse et al. 1990), at which point they diverged from $E 2 A$. This point of divergence coincided precisely with the fusion site between E2A and $P B X 1$ sequences in $t(1 ; 19)$ ALL transcripts and is known to be the $3^{\prime}$ border of $E 2 A$ exon 13 (J. Nourse and M.L. Cleary, unpubl.). The predicted E2A amino acid sequence of the HAL-01 cDNAs was identical to that reported previously (Henthorn et al. 1990; Kamps et al. 1990; Nourse et al. 1990) except for a nonconservative glycine-to-serine substitution (GGC $\rightarrow$ AGT) in codon 425 (Fig. 2A).

The sequence $3^{\prime}$ of nucleotide 1519 was not homologous to $E 2 A$ sequences nor to $P B X 1$ or closely related family members $P B X 2$ and $P B X 3$ (Monica et al. 1991). However, an open reading frame (ORF) was maintained for 91 additional codons beyond the fusion site (Fig. 2A). The protein predicted by these additional codons was not identical to previously reported proteins but shared significant similarity to the hepatic bZIP transcription factor Dbp (D-binding protein) involved in albumin gene
A

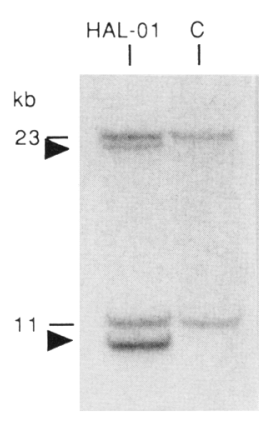

B

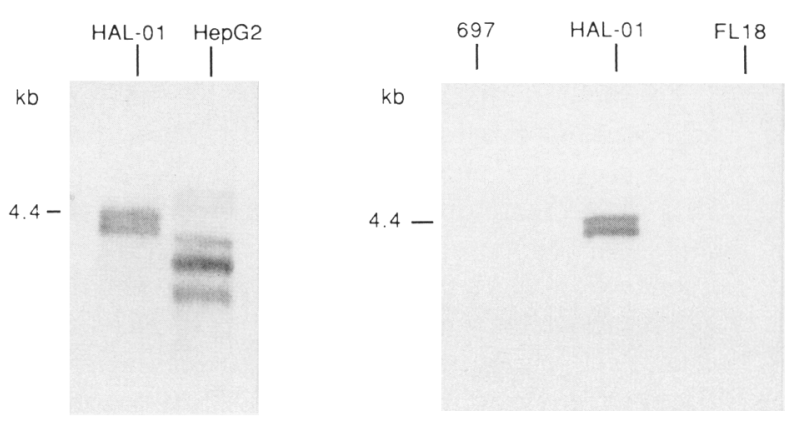

E2A

Figure 1. Blot analyses of the HAL-01 cell line demonstrating involvement of E2A and $H L F$ by $t(17 ; 19)$. (A) Southern and Northern blots hybridized with an E2A probe (E47M). (Left) Southern blot of EcoRI-digested DNA from HAL-01 and control genomic DNA (C). Dashes indicate germ-line bands of 23 and $11 \mathrm{~kb}$. E2A gene rearrangements are denoted by arrowheads. (Right) Northern blot of RNA from the $t(1 ; 19)$ ALL cell line 697 , HAL-01, and a B-lineage lymphoma cell line (FL18). Wild-type $E 2 A$ transcripts of 3.0 and $4.4 \mathrm{~kb}$ are indicated by dashes. Aberrantly sized $E 2 A$ transcripts are observed HAL-01 (4.3 and $4.1 \mathrm{~kb}$ ), and E2A-PBX1 transcripts of

HLF $8.3 \mathrm{~kb}$ are present in 697 cells. $(B)$ Northern blots hybridized with an $H L F$-specific probe. (Right) Transcripts that hybridize with the HLF probe are observed only in HAL01 and comigrate with the aberrantly sized E2A transcripts. (Left) Wild-type HLF transcripts are detected in the HepG2 hepatocellular carcinoma cell line. 
MAPVGTDKELSDLLDFSMMFPLPVTNGKGRPASLAGAQFGGSGLEDRPSSGSWGSDQSSSSFDPSRTFSEGTHFTESHSSLSSSTFLGPGLGGKSGERG 100 AYASFGRDAGVGGLTQAGFLSGELALNSPGPLSPSGMKGTSQYYPSYSGSSRRRAADGSLDTQPKKVRKVP PGLPSSVYPPSSGEDYGRDATAYPSAKTP 200 SSTYPAPFYVADGSLHPSAELWSPPGQAGFGPMLGGGSSPLPLPPGSGPVGSSGSSSTFGGLHQHERMGYQLHGAEVNGGLPSASSFSSAPGATYGGVSS 300 HTPPVSGADSLLGSRGTTAGSSGDALGKALASIYSPDHSSNNFSSSPSTPVGSPQGLAGTSQWPRAGAPGALSPSYDGGLHGLQSKIEDHLDEAIHVLRS 400 HAVGTAGDMHTLLPGHGALASGFTS $\stackrel{\star}{*}$ PMSLGGRHAGLVGGSHPEDGLAGSTSLMHNHAALPSQPGTLPDLSRPPDSYSGQGISPQRDRSRARLRFLVQDDK 500 YWARRRKNNMAAKRSRDARRLKENQ $\stackrel{*}{*}$ AIRASFLEKENSALRQEVADLRKELGKCKNILAKYEARHGPL 568

\section{B}

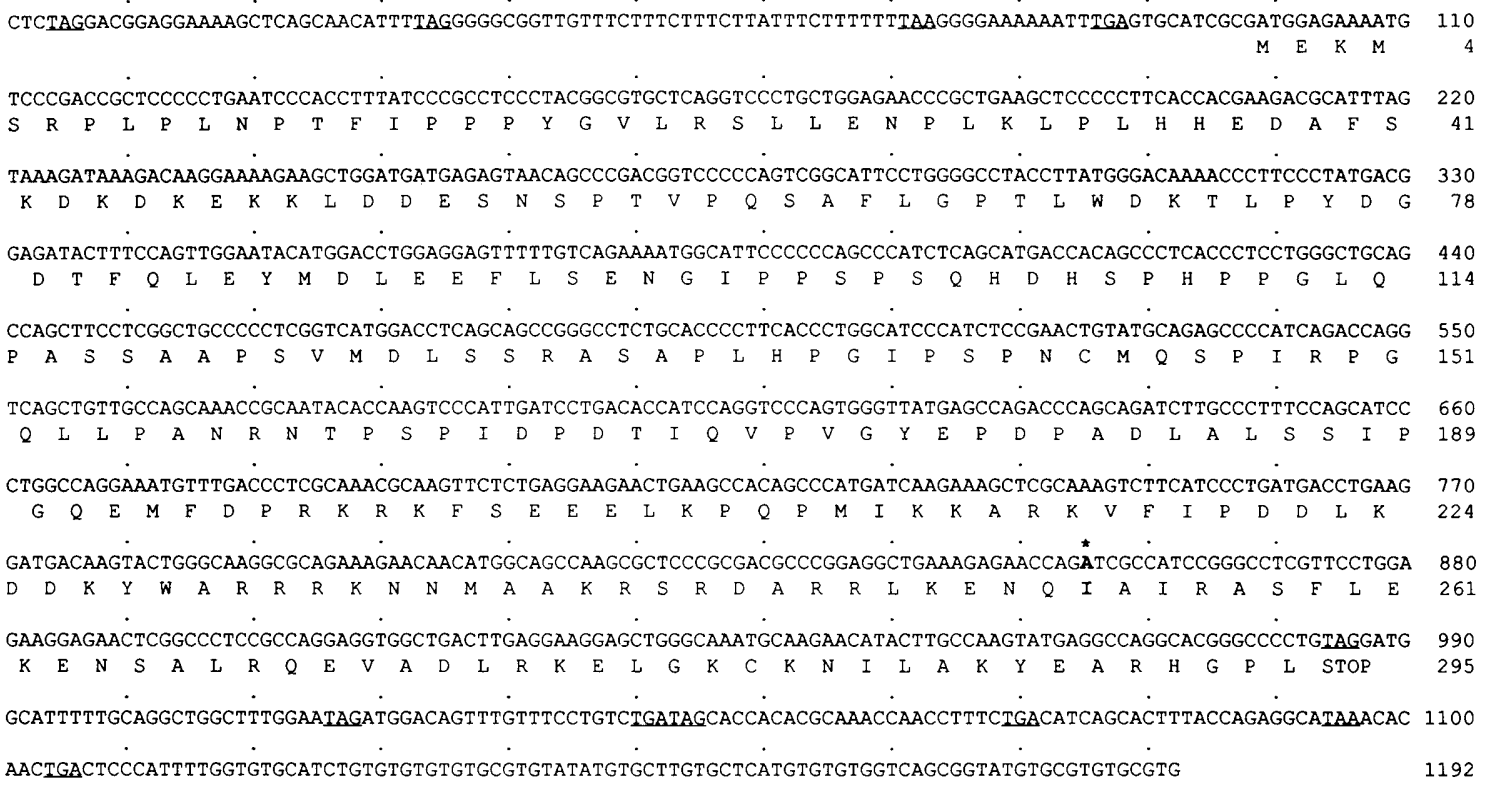

Figure 2. Sequence analyses of the E2a-Hlf fusion protein and wild-type Hlf. (A) Amino acid sequence predicted from HAL-01 fusion cDNA shown in single-letter amino acid code. The 20 -amino-acid insertion between E2a and Hlf sequences is underlined. Amino acid differences between wild-type E2a $\left(\mathrm{S}^{425}\right)$ and $\mathrm{Hlf}\left(\mathrm{F}^{526}\right)$ are indicated with asterisks $(\star)$. Numbering is according to Nourse et al. $(1990)$. $(B)$ Nucleotide and predicted amino acid sequences for wild-type Hlf. Isoleucine 253 corresponding to the first heptad repeat of the zipper is indicated by an asterisk. Stop codons preceding and following the HLF ORF are underlined.

expression through interaction with the D site (Mueller et al. 1990). Of 57 amino acids, 41 were identical between Dbp and the E2a fusion partner in a region corresponding to the Dbp basic and leucine zipper motifs (on the basis of the corrected Dbp sequence in Drolet et al. 1991; Iyer et al. 1991). The novel Dbp-related protein fused to E2a in HAL-01 therefore has features of a bZIP protein and will hereafter be referred to as Hlf.

\section{Tissue-specific expression and cloning of wild-type HLF}

Tissue-specific expression of the HLF gene was determined by Northern blot analyses on RNA isolated from human cell lines and tissues of both adult and fetal origin by use of an $H L F$-specific probe. Expression of $H L F$ was quite restricted (Table 1), as no expression was detected in normal peripheral blood mononuclear cells or in any hematolymphoid cell line examined other than HAL-01. The abundant $H L F$ transcripts detected in HAL01 comigrated with aberrant-sized $E 2 A$ transcripts, con- firming the fusion nature of these RNAs (Fig. 1B). The nontranslocated, wild-type $H L F$ gene in HAL-01 appeared to be transcriptionally silent, as all transcripts detected with the $H L F$ probe also hybridized to the E2A probe. Abundant transcription of wild-type $H L F$ RNA was observed in adult liver and the HepG2 hepatocellular carcinoma cell line (Table 1; Fig. 1B). Low levels of $H L F$ expression were also detected in adult kidney and lung. Of several fetal tissues examined, HLF expression was detected only in fetal liver, at levels significantly lower than that seen in adult liver.

To further characterize $H L F$, cDNAs for wild-type $H L F$ were isolated from a HepG2 cDNA library. Nucleotide sequence analyses of a 3-kb cDNA predicted an ORF of 885 nucleotides that overlapped at its $3^{\prime}$ end with the $3^{\prime}$ sequences present in the E2A-HLF fusion sequence from HAL-01 (Fig. 2B). A wild-type Hlf protein of 295 amino acids was predicted by this ORF, which starts at an ATG codon in a favorable configuration for initiation of translation (Kozak 1987). Stop codons were ob- 
Table 1. Expression of HLF

\begin{tabular}{|c|c|}
\hline Cell line/tissue & $H L F$ mRNA expression \\
\hline \multicolumn{2}{|l|}{$\begin{array}{l}\text { Hematolymphoid cells } \\
\text { lymphoid cell lines }\end{array}$} \\
\hline $\begin{array}{l}\text { HAL-0I } \\
\text { mature B-cell lines }\end{array}$ & $++^{a}$ \\
\hline (607B, FL18, DUL5) & - \\
\hline precursor B-cell lines & \\
\hline (697, KJ, HB, RCH-ACV) & - \\
\hline $\begin{array}{l}\text { mature } T \text {-cell lines (Molt } 4 \text { ) } \\
\text { early } T \text {-cell lines }\end{array}$ & - \\
\hline$(8402 \mathrm{~T}, \mathrm{NL}, \mathrm{JH})$ & - \\
\hline \multicolumn{2}{|l|}{ nonlymphoid cell lines } \\
\hline myeloid (HL60, U937) & - \\
\hline erythroid (K562) & - \\
\hline \multicolumn{2}{|l|}{ indeterminate lineage } \\
\hline (DHLl, TS, DU528) & - \\
\hline \multicolumn{2}{|l|}{ normal peripheral blood } \\
\hline lymphocytes & - \\
\hline \multicolumn{2}{|l|}{ Nonhematolymphoid cell lines } \\
\hline fibroblast $|293 \mathrm{~S}\rangle$ & - \\
\hline epithelial (PA-1, A431, MCF7) & - \\
\hline neuroectodermal (HS683, Al72) & - \\
\hline \multicolumn{2}{|l|}{ hepatocellular carcinoma } \\
\hline (HepG2) & ++ \\
\hline \multicolumn{2}{|l|}{ Adult tissues } \\
\hline liver & ++ \\
\hline lung & $+1-$ \\
\hline kidney & $+1-$ \\
\hline ovary & - \\
\hline placenta & - \\
\hline heart & - \\
\hline brain & - \\
\hline pancreas & - \\
\hline \multicolumn{2}{|l|}{$\begin{array}{l}\text { Fetal tissues (18-22 weeks } \\
\text { gestational age) }\end{array}$} \\
\hline liver & $+1-$ \\
\hline intestine & - \\
\hline brain & - \\
\hline lung & - \\
\hline kidney & - \\
\hline
\end{tabular}

HLF transcript expression was measured by Northern blot analysis. The integrity of all RNAs was confirmed by hybridization with a human actin cDNA probe. Symbols: $(++)$ Abundant mRNA visible after $2-4 \mathrm{hr}$ of exposure; $1+1-1$ mRNA detected only after prolonged exposure; $|-|$ no mRNA detected after at least 3 days of exposure.

${ }^{a}$ Abundant E2A-HLF fusion mRNA but no wild-type $H L F$ mRNA.

served in all three reading frames in the 100 nucleotides upstream of the initiating ATG. Several different poly(A) sites were observed in both wild-type $H L F$ and $E 2 A-H L F$ fusion cDNAs (data not shown), presumably accounting for the different-sized RNA species detected by Northern blot analysis (Fig. 1).

Comparison of E2A, HLF, and E2A-HLF sequences showed two important features that distinguished them, in addition to the previously mentioned glycine-toserine substitution. First, there were 57 nucleotides in $E 2 A-H L F$ between the E2A and HLF portions that did not match either of the corresponding wild-type sequences, indicating that a 20-amino-acid insertion of unknown origin was present in the fusion protein /underlined in Fig. 2A). Second, wild-type Hlf contained an isoleucine at amino acid 253 (Fig. 2B) compared to a phenylalanine at the equivalent position in E2a-Hlf (amino acid 526 in Fig. 2A). This missense mutation was confirmed by sequencing multiple independently isolated $E 2 A-H L F$ and wild-type $H L F$ cDNAs. Isoleucine appeared to be the wild-type amino acid, as an isoleucine is also found at this position in Dbp and Tef/Vbp (Mueller et al. 1990; Drolet et al. 1991; Iyer et al. 1991), which are significantly similar to Hlf in this region (see below).

\section{Hlf shows sequence similarity to a subfamily of bZIP transcription factors}

Data base searches indicated that Hlf is most similar to three previously described bZIP proteins: Dbp, a recently described transcription factor that binds to the $D$ box in the albumin promoter (Mueller et al. 1990); Tef, a bZIP factor involved in thyrotroph differentiation (Drolet et al. 1991); and Vbp, involved in vitellogenin II gene expression, which appears to be the chicken homolog of Tef (Iyer et al. 1991). The region of highest similarity between these proteins lies within a basic region involved in mediating sequence-specific DNA binding and a dimerization motif with features of a modified leucine zipper containing isoleucine and cystine residues in place of leucines in the first and fifth heptad repeats (Fig. 3). However, Dbp and Tef/Vbp are also extensively similar to each other in a proline and acidic amino-acid-rich region (called PAR) that distinguishes this subfamily from other bZIP proteins (Drolet et al. 1991). Because a PAR homology domain is also present in Hlf, it constitutes a third member of the PAR subfamily. The carboxy-terminal 138 amino acids of each protein, which include the entire bZIP region and the upstream PAR domain (as defined by Drolet et al. 1991), are $73 \%$ identical between Hlf and Tef, $68 \%$ identical between Hlf and Dbp, and $65 \%$ identical between Dbp and Tef. The homology between PAR family members within the $\mathrm{bZIP}$ region is far greater than is the similarity with other bZIP proteins such as C/EBP, c-Fos, c-Jun, CREB, and Gcn4 (cf. Drolet et al. 1991). Amino-terminal to the PAR region, the sequences diverge (data not shown); however, another region of significant homology exists from amino acid 42 to 101 of Hlf. Within this region, Hlf is much more similar to Tef/Vbp (62\% identical) than it is to Dbp.

\section{A 57-nucleotide insertion in E2A-HLF fusion RNA originates from the breakpoint introns of $\mathrm{E} 2 \mathrm{~A}$ and HLF}

Nucleotide sequence analysis of germ-line chromosome 19 DNA, where the HAL-01 $t(17 ; 19)$ breakpoint occurred, indicated that the first 20 nucleotides of the cDNA insertion originated from the E2A breakpoint intron (Fig. 4A). These 20 nucleotides are flanked on their $5^{\prime}$ side by sequences characteristic of a $3^{\prime}$ intron $/ 5^{\prime}$ exon 


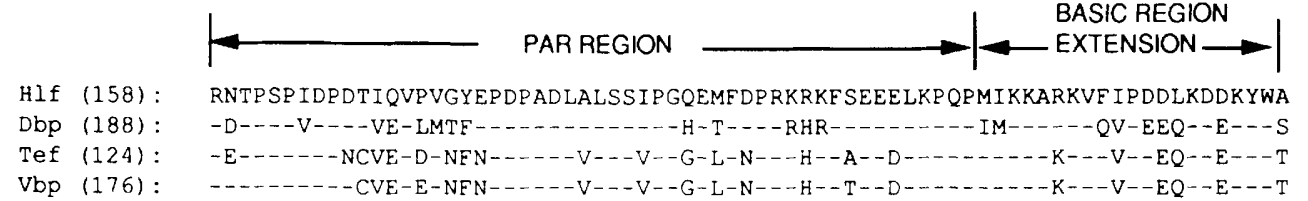

\section{BASIC REGION |HINGE - LEUCINE ZIPPER $\longrightarrow$ -}

Hlf (232):

Dbp (262):

Tef (198):

$\operatorname{Vbp}(250)$ :

bZIP

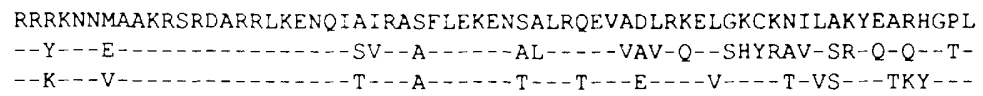

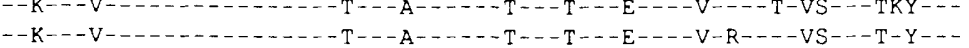

$B B$ BN AA $B \quad R \quad B B$
(295)

(325)

(261)

(313)

Figure 3. Homology of Hlf to the PAR subfamily of bZIP proteins. The region of homology between Hlf, Tef, Vbp, and Dbp is subdivided into a PAR region as defined by Drolet et al. (1991), a PAR-specific basic region extension, the bZIP basic region as defined by Vinson et al. (1989), the "hinge" which separates the basic and zipper regions, and a leucine zipper domain. Sequences are from human (Hlf), rat (Tef, Dbp), and chicken (Vbp). Dashes indicate identical amino acids shared with Hlf. For the bZIP consensus sequence (Vinson et al. 1989): (B) basic amino $\operatorname{acid}_{i}(\mathrm{~N})$ asparagine; $(\mathrm{A})$ alanine; $(\mathrm{R})$ arginine; $(\mathrm{L})$ leucine. Spaces indicate that there is no consensus amino acid at respective positions. Numbers indicate amino acid positions.

border, consisting of a pyrimidine-rich region followed by an AG dinucleotide (Mount 1982). Immediately 3' of these 20 nucleotides, 7 nucleotides showed features similar to heptamer motifs that serve as signal sequences for the immunoglobulin/TCR (IG/TCR) recombinase (Aplan et al. 1990; Brown et al. 1990). These data suggested that at least a portion of the insertion originated from a cryptic exon present in the $E 2 A$ breakpoint intron and suggested a possible role for aberrant IG/TCR recombinase activity in causation of $t(17 ; 19)$.

A polymerase chain reaction (PCR) approach was used to show that the 57-bp E2A-HLF insertion constitutes the junction of chromosome 17 and 19 sequences at the $t(17 ; 19)$ breakpoint. Oligonucleotide primers homologous to portions of the insertion ( $\mathrm{I}^{\prime}$ ' and $\mathrm{I} 3^{\prime}$ in Fig. 4A) and chromosome 19 genomic DNA flanking the insertion (INS-US and INS-DS) were employed. With $15^{\prime} / 3^{\prime}$ primers, a $57-\mathrm{bp}$ amplification product was observed in both the E2A-HLF fusion CDNA and HAL-01 genomic DNA but not in other genomic DNAs (Fig. 4B). The INSUS/I3' primer pair amplified a product of the predicted size (141 bp) only when HAL-01 genomic DNA was used as template. A 275 -bp product was amplified from all genomic DNAs (but not the fusion cDNA) with the INSUS/INS-DS primer pair homologous to intron sequences surrounding the breakpoint. These data indicated that the $57-b p$ insertion directly spans the $t(17 ; 19)$ breakpoint in HAL-01 DNA. Although not directly demonstrated by these studies, the $3^{\prime} 37 \mathrm{bp}$ of the insertion are likely derived from $H L F$ intron sequences at the breakpoint or, perhaps, from a combination of $H L F$ sequences and potential " $N$ " nucleotide insertions frequently present at recombinase-mediated translocation breakpoints (Aplan et al. 1990; Brown et al. 1990). The junction of chromosome 17 and 19 sequences is apparently recognized as a cryptic exon during RNA splicing of the E2A-HLF fusion transcript.
Hlf binds DNA specifically as a homodimer or as a heterodimer with other PAR proteins

Because Hlf is highly homologous to Tef/Vbp and Dbp within the basic region that mediates sequence-specific DNA binding in other bZIP proteins (Agre et al. 1989), we hypothesized that Hlf might also bind DNA sequences recognized by Tef / Vbp or Dbp. Electrophoretic mobility-shift assays (EMSAs) were performed with in vitro-translated Hlf with a radiolabeled oligonucleotide containing the Tef recognition element present in the rat growth hormone $(\mathrm{GH})$ promoter as described by Drolet et al. \{1991\}. Hlf bound to the GH site resulting in a major shifted DNA-protein complex (Fig. 5A); minor faster migrating bands were presumed to result from translation initiation at alternative sites of degradation. The binding was specific because it was effectively competed with excess unlabeled GH oligonucleotide and, to a lesser extent, by the albumin D site (Mueller et al. 1990) or an optimized Vbp site (Iyer et al. 1991), which are binding sites for similar PAR proteins. The Fos serum response element (SRE), which has recently been shown to contain a functional C/EBP site (Metz and Ziff 1991), competed much less effectively. No competition was observed with two unrelated oligonucleotides. Although the GH TEF site does not necessarily represent the optimal site, the results indicated that Hlf specifically and preferentially bound the GH site under these experimental conditions. Thus, subsequent DNA-binding studies were carried out under similar conditions.

As PAR and bZIP proteins bind DNA as dimers (Kouzarides and Ziff 1988; Gentz et al. 1989; Turner and Tjian 1989; Vinson et al. 1989; Drolet et al. 1991; Iyer et al. 1991), the dimerization potential of Hlf was assayed by EMSA following cotranslation of wild-type Hlf and a truncated version of Hlf $\left(\mathrm{Hlf}^{\Delta \mathrm{N} 3-155}\right)$. When assayed individually, Hlf and Hlf ${ }^{\Delta \mathrm{N}}$ demonstrated different mobil- 
A

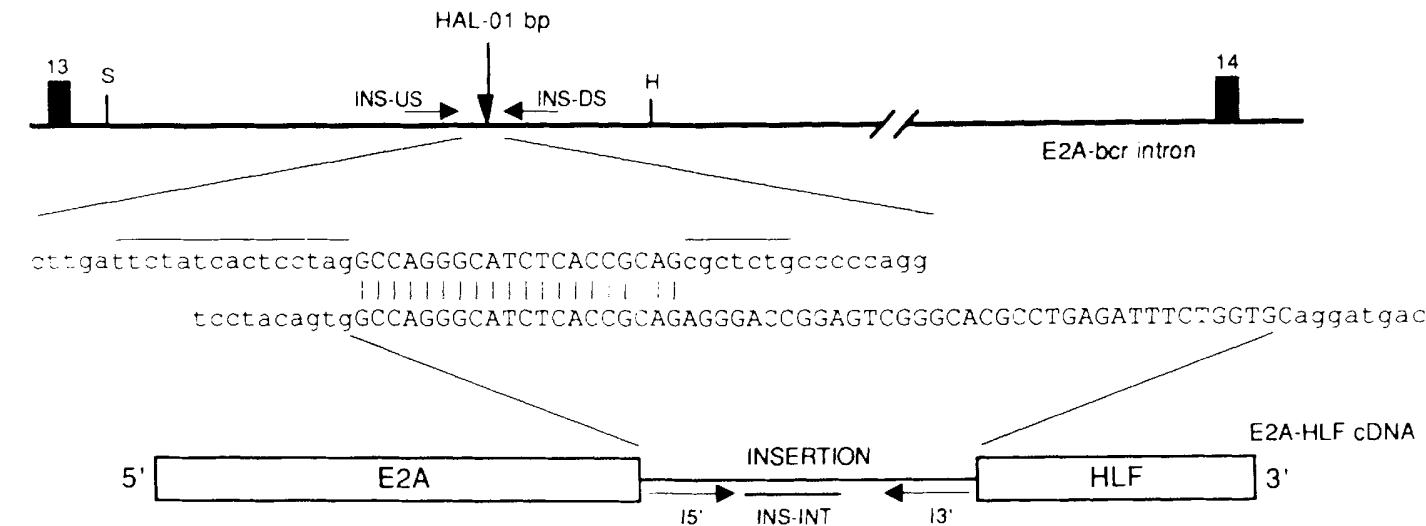

B
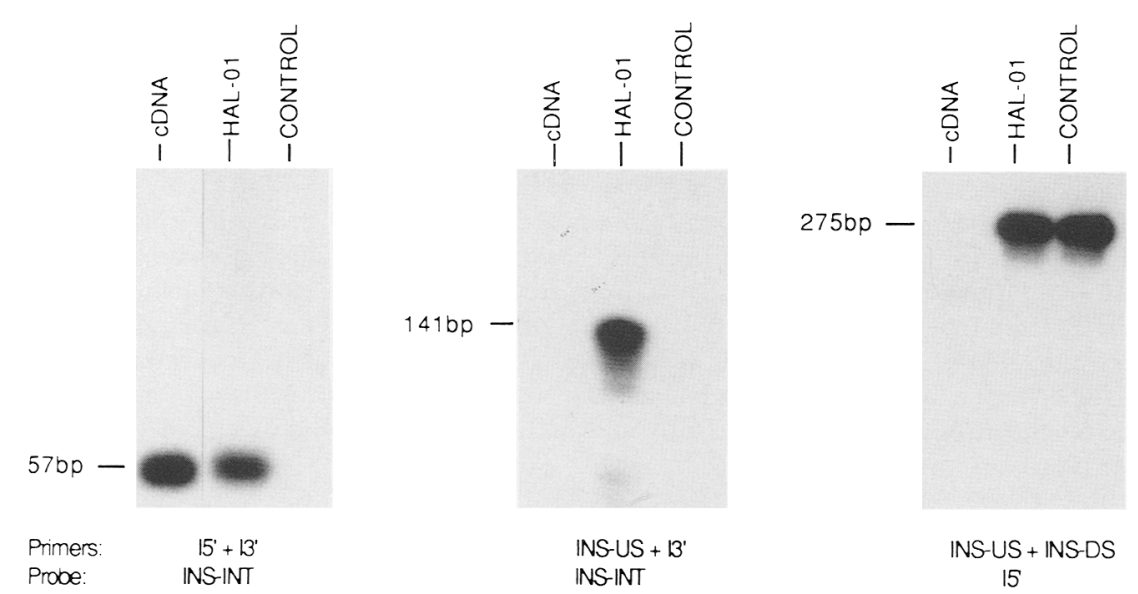

Figure 4. Genomic origin of insertion sequences present in $E 2 A-H L F$ fusion cDNA. $(A)$ The E2A-bcr intron between exons (solid boxes) 13 and 14 is depicted at the top. $(\mathrm{S}, \mathrm{H}) \mathrm{SacI}$ and HindIII restriction sites, respectively. A schematic illustration of the E2A-HLF fusion cDNA appears at the bottom. Sequences show nucleotides comprising insertion (uppercase letters) in chromosome 19 germ-line DNA (top) and HAL-01 fusion cDNA (bottom). The consensus 3' splice site and heptamer are overlined. The relative positions of the PCR amplification and detection oligonucleotides are indicated by arrows and lines, respectively. $(B \mid$ PCR analysis demonstrating juxtaposition of germ-line chromosome 19 and nonchromosome 19 DNA sequences at the $t(17 ; 19)$ breakpoint in HAL-01. Input DNA consisted of E2A-HLF fusion cDNA (CDNA), HAL-01 genomic DNA (HAL-01), or control genomic DNA (control). Amplification and detection oligonucleotides are indicated below panels. The sizes (in bp) of the PCR products are indicated at left.

ities (Fig. 5B). Cotranslation of Hlf and $\mathrm{Hlf}^{\Delta \mathrm{N}}$ resulted in a third complex with an intermediate mobility, indicating that Hlf binds specifically to DNA as a dimer similar to other bZIP proteins.

The heterodimerization potential of Hlf was assessed similarly. When assayed individually, Tef and Hlf ${ }^{\Delta \mathrm{N}}$ showed distinct mobilities by EMSA /a deleted Hlf protein was assayed because Tef and wild-type Hlf overlapped in their mobilities). Cotranslation of Tef and Hlf $^{\Delta \mathrm{N}}$ demonstrated a complex with intermediate mobility whose binding could be effectively competed with an excess of the GH site (Fig. $5 \mathrm{C}$ ). Because Dbp has been shown in earlier studies to bind the GH site employed for our studies (Drolet et al. 1991), its potential dimerization with Hlf was also assessed by EMSA. Dbp and wild-type Hlf showed distinct mobilities and, when cotranslated, resulted in the appearance of a complex with intermediate mobility (Fig. 5D). These data are in- dicative of DNA binding by Hlf-Tef and Hlf-Dbp heterodimers, respectively.

\section{E2a-Hlf preferentially binds DNA as a heterodimer with PAR proteins}

Having established that Hlf specifically binds DNA as a homodimer or as a heterodimer with other PAR bZIP proteins, the DNA-binding properties of the $t(17 ; 19) \mathrm{fu}$ sion protein $\mathrm{E} 2 \mathrm{a}-\mathrm{Hlf}$ were compared under identical conditions. EMSA analysis of E2a-Hlf demonstrated very poor binding to the GH TEF site, which is not evident in Figure 6A but was apparent on longer exposures (Fig. 7B, lane 1). In contrast, cotranslation of E2a-Hlf with Tef showed a readily apparent complex with slower migration than the Tef homodimer that was specifically competed with an excess of the GH site (Fig. 6A). This complex consisted, at least in part, of E2a-Hlf, as demon- 

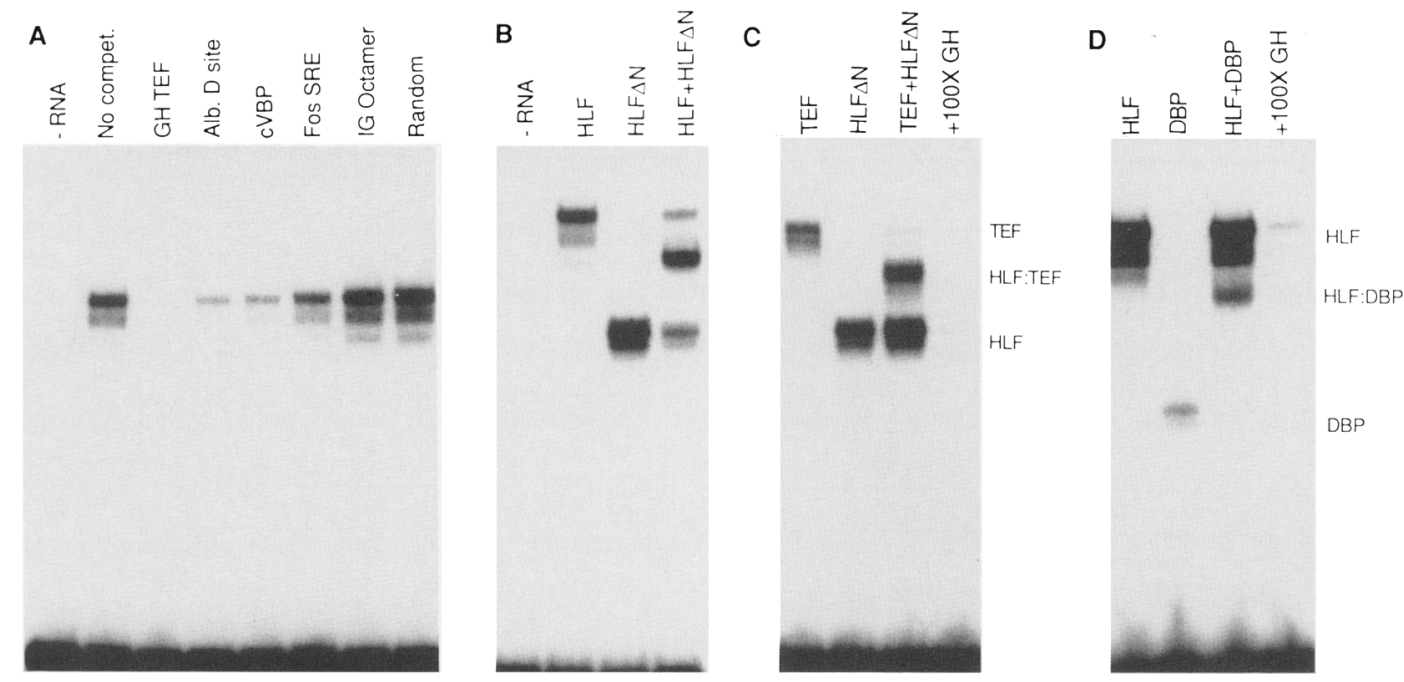

Figure 5. DNA-binding analyses of wild-type Hlf homodimers and heterodimers. $(A)$ Mobility-shift analysis of in vitro-translated Hlf with a radiolabeled double-stranded oligonucleotide corresponding to the rat GH promoter TEF site. One hundred-fold molar excesses of the indicated oligonucleotides were added to each binding reaction as indicated. $(B)$ Mobility-shift analysis of in vitro-translated wild-type Hlf $\langle$ HLF), an Hlf deletion mutant containing the PAR, basic, and leucine zipper domains (HLF $\Delta N$ ), or wild-type Hlf cotranslated with Hlf ${ }^{\Delta N}$ (HLF + HLF $\left.\Delta N\right)$. $\{C$ ) Interaction of HIf and Tef on the TEF GH recognition element. Wild-type Tef (TEF) or a truncated Hlf (HLF $\Delta N)$ was translated independently or cotranslated in vitro and analyzed for DNA binding by EMSA. The positions of Hlf, Dbp, and Hlf-Dbp are indicated at right. $(100 \times \mathrm{GH}) \mathrm{A}$ binding reaction with cotransfected Tef and Hlf $\mathrm{fN}^{\Delta \mathrm{N}}$ in the presence of 100-fold molar excess of unlabeled probe. $(D)$ Interaction of HIf and Dbp on the TEF GH recognition element. Wild-type Hlf (HLF), or $\mathrm{Dbp}$ ) (DBP) were translated independently or cotranslated in vitro and analyzed for DNA binding by EMSA. The positions of Hlf, Dbp, and Hlf-Dbp are indicated at right.

strated by its loss in the presence of anti-E2a antisera but not with nonimmune sera, whereas the Tef homodimer was unaffected by either sera (Fig. 6A). Cotranslations of E2a-Hlf with Dbp or wild-type Hlf (Fig. 6B,C) also showed slower migrating complexes whose formation was specifically inhibited in the presence of anti-E2a sera. These data indicate that E2a-Hlf binds DNA in a heterodimeric complex with other PAR proteins. Mini-
Figure 6. DNA-binding analyses of E2aHlf. $\{A \mid$ Interaction of E2a-Hlf with Tef on the GH promoter TEF site. Mobility-shift analysis of E2a-Hlf (lane 1) translated individually was compared with Tef (lane 2) or cotranslation of E2a-HIf and Tef (lanes 3-6). Migrations of E2a-Hlf : Tef heterodimer (HD) and Tef homodimer (TEF) complexes are indicated. Binding reactions were performed with an excess of unlabeled TEF site (lane 4), in the presence of nonimmune sera (lane 5) or anti-E2a sera (lane 6). (B) Mobility-shift analysis of Hlf translated individually (lane 1) or cotranslated with E2a-Hlf (lane 2). Heterodimer $(\mathrm{HD})$ formation was prevented in the presence of anti-E2a sera (lane 3). Approximately 10 -fold excess of Hlf protein was present in the binding reactions. $(C)$ Interaction of E2a-Hlf with Dbp. Mobility-shift analysis of Dbp and E2a-Hlf cotranslation products shows a heterodimer complex (lane 2) that is specifically inhibited by anti-E2a sera (lane 3). (D) Endogenous E2a-Hlf complex in HAL-01 cells. Mobility-shift analysis with nuclear extracts showed several complexes binding to the GH TEF site (lane 1) that were specifically competed with excess binding site (lane 2). One complex containing E2a-Hlf (arrow) was formed in the presence of nonimmune sera (lane 3) but not when anti-E2a antibodies were included in the binding reaction (lane 4).
A

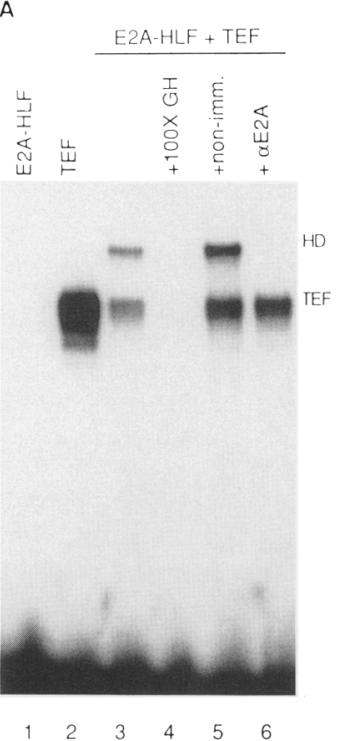

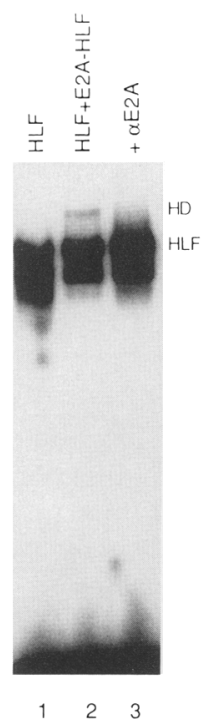

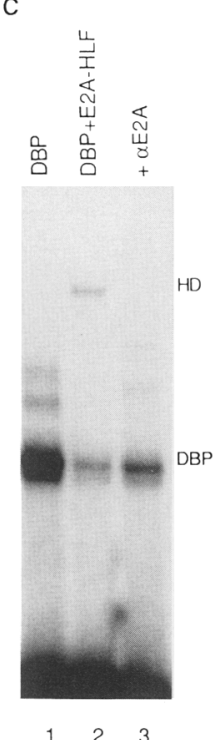

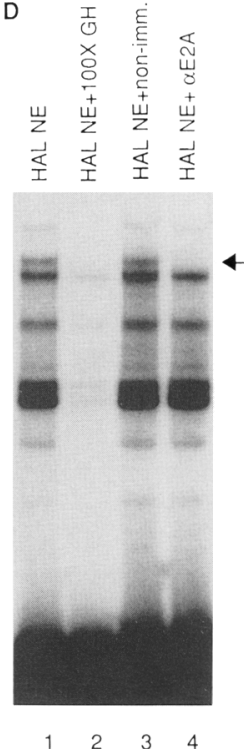


mal binding observed with E2a-Hlf alone suggested that the $t(17 ; 19)$ fusion protein isolated from HAL-01 differed from wild-type Hlf in its binding and/or dimerization properties.

\section{A zipper mutation alters the DNA-binding properties of E2a-Hlf}

Sequence comparison of E2a-Hlf with other PAR proteins including wild-type Hlf (Figs. 2A and 3) showed that a missense mutation had converted an isoleucine to phenylalanine in the first heptad repeat of the leucine zipper of E2a-Hlf. As previous studies have shown that mutations in the leucine zipper can have profound consequences on dimerization and DNA-binding properties of bZIP proteins, the effect of this nonconservative amino acid alteration in E2a-HIf was assessed further. Various forms of Hlf and E2a-Hlf (Fig. 7A) were translated in vitro and tested for DNA binding by EMSA. A mutant fusion protein (E2a-Hlf $)$ in which $\mathrm{F}^{526}$ was converted to an isoleucine by site-directed mutagenesis showed significantly greater binding to the TEF site than E2a-Hlf under these conditions (Fig. 7B, lanes 1,2 ). The reduced DNA binding observed for E2a-Hlf was not the result of less protein in the reaction, as equal amounts of input protein were confirmed by SDS-PAGE of radiolabeled in vitro translates (data not shown). The contribution of the $\mathrm{I} \rightarrow \mathrm{F}^{526}$ change to DNA binding was assessed further by analysis of a mutant Hlf protein containing an $\mathrm{I} \rightarrow \mathrm{F}^{253}$ substitution in the analogous zipper residue of wild-type Hlf. The Hlf ${ }^{\mathrm{F}}$ mutant showed significantly poorer binding than wild-type Hlf, as evidenced by at least a 100-fold reduction in the amount of shifted complex on EMSA (Fig. 7B, lanes 3,4). However, Hlf $^{\mathrm{F}}$ retained an ability to bind DNA in a complex with $\mathrm{Hlf}^{\Delta \mathrm{N}}$ containing a wild-type zipper, although the shifted $\mathrm{Hlf}^{\mathrm{F}}$ : Hlf ${ }^{\Delta \mathrm{N}}$ complex was reduced about fourfold compared with binding by an Hlf : Hlf ${ }^{\Delta \mathrm{N}}$ complex with no zipper mutations (Fig. 7B, lanes 5-7). These data indicated that the $\mathrm{I} \rightarrow \mathrm{F}$ mutation in the first position of the zipper had a significant effect on DNA binding as assessed by EMSA.

\section{E2a-Hlf shows altered DNA-binding affinity compared with wild-type Hlf independent of the zipper mutation}

In addition to the basic region conserved among the entire bZIP family, Hlf shares with other PAR proteins an upstream cluster of basic amino acids (Fig. 3) that has been shown to contribute to the DNA-binding specificity of Tef (Drolet et al. 1991). However, this PAR-specific basic cluster was not present in the E2a-Hlf fusion protein, possibly contributing to additional alterations in the DNA-binding properties of E2a-Hlf compared with wild-type Hlf. To evaluate the relative DNA-binding affinities of Hlf and the $t(17 ; 19)$ fusion product, competition analyses with mobility-shift assays were performed with in vitro-translated proteins. For these studies the E2a-Hlf ${ }^{\mathrm{I}}$ fusion protein was employed to assess DNA- binding properties independent of the effects of the leucine zipper mutation. The affinity of E2a-Hlf ${ }^{\mathrm{I}}$ for the $\mathrm{GH}$ DNA recognition sequence was decreased $\sim 10$-fold compared with wild-type Hlf, as demonstrated by the greater competitor DNA concentrations required for equivalent reductions in maximal binding by E2a-Hlf (Fig. 8). The observed reduction in binding affinity is similar to that reported for Tef PAR-specific basic region mutants and supports a similar role for this region in the DNA-binding specificity of Hlf. These data showed that fusion of Hlf to E2a resulted in altered DNA-binding properties (at
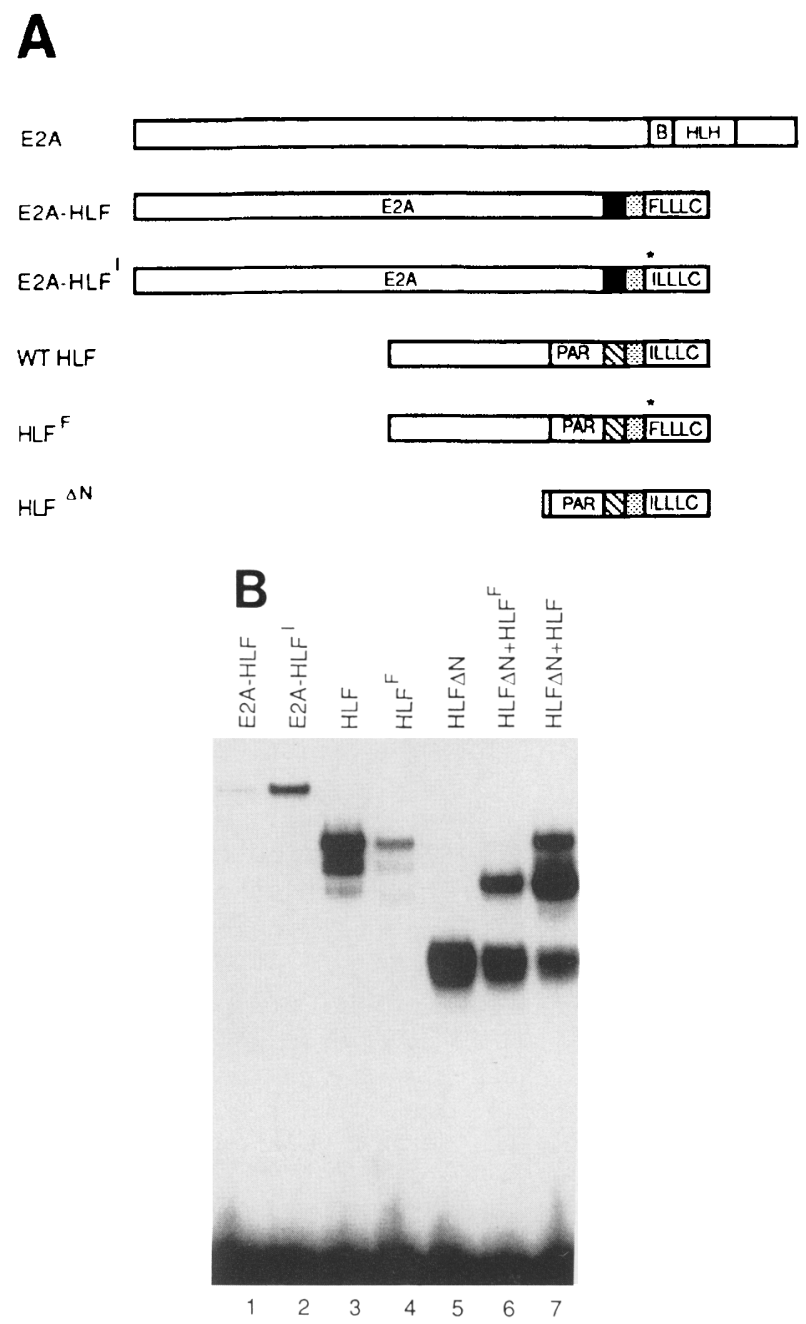

Figure 7. A zipper mutation affects DNA-binding properties of E2a-Hlf. $(A)$ Schematic representation of E2a, E2a-Hlf, wildtype Hlf, and mutant proteins translated in vitro for mobilityshift assays. Stippled boxes denote basic region; hatched boxes indicate a PAR-specific basic region that is replaced by insertion (D) in fusion protein. (B) Mobility-shift analyses of E2a-Hlf, the

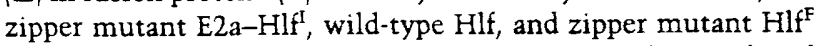
translated individually (lanes $1-4$, respectively) show reduced binding by $\mathrm{F} / \mathrm{F}$ homodimers containing an $\mathrm{I} \rightarrow \mathrm{F}$ mutation in zippers. DNA binding of $F / I$ heterodimers was assessed by mobility-shift analysis of the Hlf ${ }^{\mathrm{F}}$ : HIf ${ }^{\Delta \mathrm{N}}$ complex (lane 6) compared with the wild-type Hlf : Hlf ${ }^{\Delta N}$ (lane 7) complex following cotranslation. 


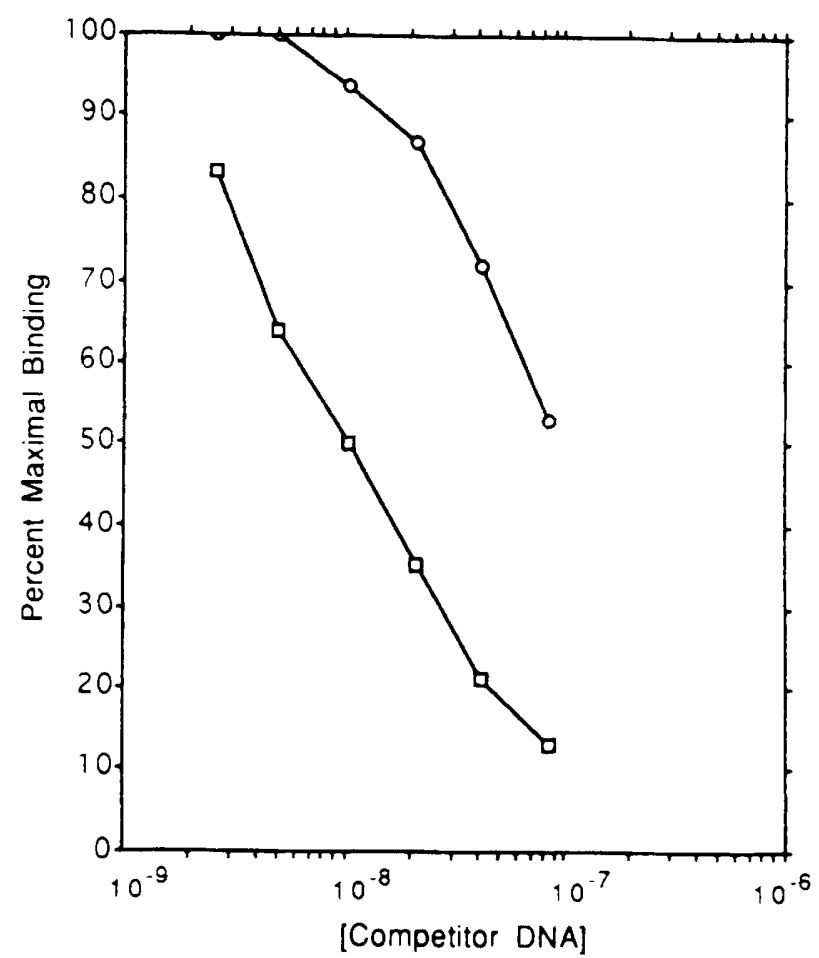

Figure 8. Alteration of HIf DNA-binding affinity following fusion to E2a. Competition curves are shown for wild-type Hlf and E2a-Hlf ${ }^{I}$ DNA binding to the TEF GH site in the presence of increasing concentrations of identical but unlabeled TEF GH site. Quantitation of bound DNA was determined with a computer-controlled imaging system (AMBIS). Molar concentrations of competitor are indicated. (O) E2a-HLF; $(\square)$ wild-type HLF.

least for the GH TEF site) independent of the effect of the zipper mutation. The potential additive contribution of the $\mathrm{I} \rightarrow \mathrm{F}$ substitution to reduced DNA-binding affinity could not be measured directly as E2a-Hlf homodimers did not bind DNA sufficiently to quantitate in EMSA competitor assays.

\section{An endogenous E2a-Hlf complex is present in $\mathrm{HAL}-01$ cells}

Gel-shift analysis of nuclear proteins isolated from the HAL-01 cell line showed several shifted complexes with the GH TEF site whose binding was specifically competed with an excess of unlabeled probe (Fig. $6 \mathrm{D})$. The possible presence of E2a-Hlf in the shifted complexes was assessed by using anti-E2a antibodies. EMSA of binding reactions that contained E2a-specific antibodies showed loss of a major shifted complex when compared with reactions performed with nonimmune sera (Fig. 6D, lanes 3,4$)$. This complex showed a migration comparable to those observed with in vitro-translated heterodimers of E2a-Hlf and other PAR proteins. Most of the complexes that bound the GH TEF site in HAL-01 nuclear extracts showed no alteration in their mobilities or abundance in the presence of anti-E2a antibodies. These data indicated that HAL-01 contains an endogenous complex consisting, at least in part, of E2a-Hlf capable of binding to the GH TEF site in addition to several other complexes that appear to be unassociated with the fusion protein.

\section{Discussion}

Although the $t(17 ; 19)$ translocation is relatively uncommon, current studies show that it has unusual features with importar.t implications for the role of transcription factors in leukemogenesis. In the HAL-01 cell line, $t(17 ; 19)$ results in fusion of the $E 2 A$ gene with a previously undescribed gene that codes for a novel bZIP protein called Hlf. These features are similar to the $E 2 A-$ $P B X 1$ fusion resulting from $t(1 ; 19)$ in childhood pre- $B$ ALL (Kamps et al. 1990; Nourse et al. 1990). In both types of translocations, the chimeric proteins contain identical portions of E12/E47 that experimentally function as a transcriptional activation domain when fused to a heterologous DNA-binding element (Henthorn et al. 1990). The translocation partner in each case contributes a DNA-binding domain: a basic region/zipper in the case of Hlf and a homeo domain in the case of Pbxl. However, $\mathrm{E} 2 \mathrm{a}-\mathrm{Hlf}$ is distinguished from $\mathrm{E} 2 \mathrm{a}-\mathrm{Pbxl}$ and other translocation-associated proteins in that it has measurably altered DNA-binding properties compared with its wildtype equivalent. Although the $t(15 ; 17)$ Pml-Rar $\alpha$ protein has altered trans-activation properties (de The et al. 1991; Kakizuka et al. 1991; Pandolfi et al. 1991), there is no indication that these result from differences in DNA binding by the chimera.

\section{An E2a-Hlf insertion mutation results from inclusion of a cryptic breakpoint-containing exon in the fusion RNA}

A feature of the $t(17 ; 19)$ fusion RNA that has not been described previously in leukemic translocations is the inclusion of intron sequences surrounding the genomic breakpoint. The insertion is apparently recognized as a cryptic exon during splicing of the fusion RNA. No wildtype E2A RNAs have been isolated in which splicing occurred at this cryptic site (Henthorn et al. 1990; Kamps et al. 1990; Nourse et al. 1990 and unpubl.). The reason for this differential recognition is unclear; perhaps it allows for the proper spacing of E2a and Hlf protein domains or maintains an open translational reading frame in the chimeric RNA. The remaining portion of the insertion ( 37 nucleotides) is not a feature of wild-type Hlf; however, we cannot exclude the possibility that alternative splicing of $H L F$ may occur in other tissues, as all cDNAs were isolated from the same source (HepG2).

Sequences in the E2A-breakpoint cluster region (bcr) intron flanking the HAL-01 breakpoint show homology to heptamer signal sequences consistent with the possibility that the $t(17 ; 19)$ resulted from aberrant recombinase activity. In support of this, HAL-01 cells show features of precursor B cells arrested at a point in B-cell maturation when recombinase is expressed because they 
contain rearranged immunoglobulin heavy-chain genes but no detectable rearrangements of Igא or TCR $\beta$ genes. The specific genomic sequence constraints observed in HAL-01 $t(17 ; 19)$, that is, crossover at a consensus heptamer adjacent to a cryptic splice site, may account for the infrequent occurrence of this translocation in ALL.

\section{Hlf is a new liver-associated member of the PAR subfamily of bZIP proteins}

The PAR proteins exhibit structural and functional properties establishing them as a distinct subfamily of bZIP proteins. They bind to specific target DNA sequences as homodimers or as heterodimers with other PAR family members, but not with non-PAR bZIP proteins (Drolet et al. 1991; Iyer et al. 1991). Unlike other bZIP proteins, experimental data indicate that the specificity of DNA binding of PAR family members is not only dependent on the integrity of the classic basic region itself but also on sequences located both in the extended basic region (Drolet et al. 1991) and within or amino-terminal to the PAR region (Iyer et al. 1991). Hlf exhibits properties analogous to those of the other PAR proteins; namely, it specifically binds to the TEF GH site as a homodimer or as a heterodimer with either Tef or Dbp.

Hlf represents the second example of a PAR protein expressed preferentially in hepatocytes. Despite widespread mRNA expression, the Dbp protein is present predominantly in adult liver and is down-regulated during hepatic regeneration (Mueller et al. 1990). In contrast to Hlf, $T E F / V B P$ mRNA is widely expressed in adult rat/ chicken tissues; however, protein expression has not yet been determined (Drolet et al. 1991; Iyer et al. 1991). The role of Tef/Vbp may differ during embryogenesis, as mRNA expression appears to be much more spatially limited (Drolet et al. 1991; Iyer et al. 1991). The expression pattern of Hlf, and the known role of Dbp and Vbp in regulation of liver-specific gene expression, suggests that PAR proteins may play a specific role in hepatic metabolism. Additional studies are required to determine whether these proteins interact to regulate expression of the same, or different, target genes and whether Hlf constitutes the liver-specific factor necessary for efficient Dbp activity (Mueller et al. 1990).

\section{Altered DNA binding occurs with fusion of Hlf to $E 2 a$ in $t(17 ; 19) A L L$}

In contrast to wild-type Hlf, E2a-Hlf encoded by the HAL-01 fusion cDNA bound extremely poorly to the GH site as a homodimer but readily when heterodimerized with either wild-type Hlf or other PAR proteins. This marked difference in DNA-binding properties was partially attributable to the isoleucine-to-phenylalanine mutation in the first heptad repeat position of the leucine zipper. The effect of phenylalanine on DNA binding was shown by reversion of $\mathrm{F} \rightarrow \mathrm{I}$, which improved DNA binding by the E2a-Hlf homodimer. Similarly, the I $\rightarrow$ F mutation of wild-type Hlf significantly reduced its ability to bind DNA as a homodimer. Our data do not indi- cate whether the zipper mutation is essential for oncogenesis; however, circumstantial evidence suggests that it provided a growth advantage to the subclone in which it arose.

Our data also show that E2a-Hlf demonstrates altered DNA binding to the TEF site independent of the $\mathrm{I} \rightarrow \mathrm{F}$ zipper mutation. $t(17 ; 19)$-mediated fusion resulted in loss of wild-type Hlf sequences that encode the basic region extension and regions farther amino-terminal of the classic basic region. The effects of E2a fusion on DNA binding were assessed in the $\mathrm{F} \rightarrow$ I revertent E2a$\mathrm{Hlf}^{\mathrm{I}}$, which showed significantly lower affinity for the GH TEF site compared with wild-type Hlf. These results are very similar to the altered binding of Tef mutants (in which pairs of alanines were substituted for pairs of lysines in the extended basic region of Tef) for the prolactin TEF recognition site (Drolet et al. 1991), suggesting that absence of the extended Hlf basic region in the fusion protein changes its binding properties. Additional studies are required to show whether this effect is the result of alterations in DNA-binding specificity, which may only affect interactions of E2a-Hlf with a subset of its potential binding sites or change its binding site preferences completely. These studies do not indicate whether the markedly impaired DNA binding of E2aHlf ${ }^{\mathrm{F}}$ homodimers is the result of a direct effect on protein-DNA interaction or is secondary to altered dimerization properties of the phenylalanine-containing chimera.

\section{Potential models for the role of a chimeric bZIP protein in leukemia}

A model for the role of E2a-Hlf in ALL needs to account for three primary observations. First, $t(17 ; 19)$ resulted in ectopic lymphoid expression of the Hlf bZIP domains that mediate dimerization and DNA binding. Second, in E2a-Hlf the amino-terminal portion of Hlf just upstream of the classic bZIP basic region was replaced with a portion of E2a that has properties of a trans-activation domain (Henthorn et al. 1990). Third, at least two structural alterations in E2a-Hlf reduce its DNA binding as a homodimer (at least to the TEF site). The most straightforward model is that E2a-Hlf homodimers deregulate target genes through binding to Hlf (or other PAR)-binding sites. This presupposes that the observed alterations in DNA binding are not functionally relevant or are overcome by high intracellular concentrations of E2a-Hlf. Conversely, binding alterations might expand the spectrum of target sites recognized by E2a-Hlf homodimers, leading to deregulation of a new set of target genes. We cannot rule out these possibilities as the functional relevance of altered DNA-binding affinity is undefined; furthermore, our studies employed a single binding site. Future investigations need to address the potential binding preferences of E2a-Hlf homodimers.

The alternative is that E2a-Hlf functions in vivo as a heterodimer. This requires that endogenous proteins capable of heterodimerizing with E2a-Hlf are present in lymphoid cells, a possibility supported by the detection 
of endogenous complexes in HAL-01 cells under conditions where in vitro-translated homodimers bind extremely poorly. A potential dimerization partner is Tef/ Vbp as it is known to be transcribed in lymphoid tissues of rat and chicken, respectively. It is also possible that the PAR family contains additional, as yet undiscovered, members, and perhaps one or more of these is involved in regulation of lymphoid gene transcription. Dimerization might also occur with non-PAR bZIP proteins such as Jun, Fos, or C/EBP family members present in lymphoid cells. However, previous in vitro studies suggest that heterodimerization of PAR proteins is restricted as Tef/Vbp is incapable of binding to DNA as a dimer with C/EBP (Drolet et al. 1991; Iyer et al. 1991). A potential role for the E2a-Hlf zipper mutation in relaxing dimerization specificity and allowing binding with non-PAR bZIP proteins needs to be addressed. Because of the altered DNA-binding affinity of E2a-Hlf, an endogenous dimerization partner may play an important role in directing the complex to target genes whose expression is deregulated by the E2a trans-activation domain. Alternatively, E2a-Hlf might function as a dominant-negative factor by dimerizing with and sequestering endogenous bZIP proteins. We consider the latter unlikely on the basis of the known trans-activation characteristics of the retained portion of E2a, although the transcriptional properties of E2a-Hlf remain to be determined.

Our studies show that the potential role of E2a fusion in activating transcriptional proteins in ALL is not restricted to homeo domain proteins but extends to the bZIP family. A specific oncogenic role for portions of E2a retained in both $\mathrm{E} 2 \mathrm{a}-\mathrm{Pbxl}$ and $\mathrm{E} 2 \mathrm{a}-\mathrm{Hlf}$ is suggested, but additional studies are required to define the contributions of E2a to potential transcriptional and transforming properties of these chimeras. Such investigations should provide further insights into the mechanisms by which structural and/or regulatory mutations in transcription factors induce neoplastic transformation.

\section{Materials and methods}

Cell lines

Establishment of the HAL-01 cell line from a patient with $\mathrm{t}(17 ; 19)(\mathrm{q} 21-22 ; \mathrm{p} 13)$ ALL has been described previously, along with its morphological, immunophenotypic, and cytogenetic characteristics (Ohyashiki et al. 1991). Karyotype analyses of HAL-01 indicated that the cytogenetic alterations involving chromosomes 17 and 19 have remained stable with long-term culture. Additional cell lines utilized for Northern analysis have been described previously (Nourse et al. 1990; Monica et al. 1991 .

\section{Cloning of E2A-HLF and HLF cDNAs}

To isolate fusion cDNAs from HAL-01, $3 \mu \mathrm{g}$ of poly $\mid \mathrm{A})^{+}$RNA was converted to double-stranded cDNA by use of the Superscript kit (BRL-GIBCO), as recommended by the supplier with minor modifications. Approximately 1 million recombinant phage were subjected to a differential screening procedure with E2A probes, as described previously (Nourse et al. 1990). Ten plaques that met the criteria for fusion cDNAs [hybridized with a $5^{\prime}(\mathrm{B})$ but not a $3^{\prime}(\mathrm{C})$ probe) were purified and characterized by nucleotide sequence analyses. For one fusion cDNA clone the nucleotide sequence was completely determined from $\sim 50 \mathrm{nu}$ cleotides $5^{\prime}$ of the E2A start site (nucleotide 26 in Nourse et al. 1990 ) to $\sim 200$ nucleotides beyond the $H L F$ stop codon. In five other fusion cDNA clones, the E2A-HLF fusion sites were determined and shown to be identical. Six of six independently isolated fusion cDNAs contained an identical $\mathrm{A} \rightarrow \mathrm{T}$ missense mutation converting isoleucine ( $\underline{A} T C$ ) to phenylalanine (TTC) in the first heptad repeat of the Hlf leucine zipper (amino acid 526 in Fig. 2A). Wild-type $H L F$ cDNAs were isolated from a cDNA library in $\lambda Z A P$ prepared from mRNA purified from ILlstimulated HepG 2 cells (Stratagene). Approximately 2 million plaques were screened at high stringency with an $H L F$-specific probe as described below for Northern blot hybridizations. Twelve phages were purified to homogeneity, and the phage inserts were excised and converted to double-stranded pBluescript. Portions of several clones were sequenced independently, and the entire ORF of one clone, pBSHN1A, was sequenced completely (Fig. 2B). The wild-type isoleucine in the first heptad repeat of the leucine zipper was present in six independently isolated clones of differing lengths.

\section{Plasmid constructions and mutagenesis}

The in vitro expression plasmid $\mathrm{pE} 2 \mathrm{~A}-\mathrm{HLF}$ was constructed by replacing the $3^{\prime}$ XhoI-EcoRI fragment of pSP64 $\triangle \mathrm{E} 2 \mathrm{~A}-\mathrm{PBX} 3 \mathrm{~A}$ (Monica et al. 1991) with a 3' XhoI-EcoRI fragment of the HAL2 cDNA. A two-step overlap extension PCR procedure (Zaret et al. 1990) was used to construct in vitro expression plasmid $\mathrm{pE} 2 \mathrm{~A}-\mathrm{HLF}^{\mathrm{I}}$ in which the phenylalanine in the first heptad repeat of E2a-Hlf was converted to an isoleucine as is found in the wild-type Hlf. All constructions were confirmed by restriction enzyme analysis, and those involving PCR were analyzed by nucleotide sequencing to ensure that no mutations had occurred during construction.

A construct for optimal in vitro expression of wild-type Hlf was constructed by PCR with pBSHNIA as a template and primers DB-1 \{5'-CCAAAGCTAGCCTGCAAAAATGCC-3'\} and HAL4 (5'-GAAAGCTTCGCGATGGAGAAAATGTCC$\left.3^{\prime}\right)$, and the PCR product was cloned into the HindIII and $\mathrm{XbaI}$ sites of pSP64. An Hlf mutant $\left(\Delta \mathrm{N}^{3-155} \mathrm{HLF}\right)$ lacking amino acids 3-155 was constructed by PCR with pBSHNlA as a template and primers DB-1 and HLF1 (5'-GAAAGCTTCGCGATGGAGGCAAACCGCAATACACCAAGTC-3'), and the PCR product was inserted into HindIII and $X b a I$ sites of pSP64. The in vitro expression plasmid $\mathrm{pHLF}^{\mathrm{F}}$ was constructed by overlap extension PCR to convert the isoleucine of the first heptad repeat in the leucine zipper of wild-type Hlf to a phenylalanine. In vitro expression plasmids for TEF (pMET3-TEF) and DBP (pCMVDBP) have been reported previously (Mueller et al. 1990; Drolet et al. 1991).

\section{PCR}

Amplifications of specific sequences were performed in a Perkin-Elmer programmable thermocycler with commercially prepared reagents (Perkin-Elmer Cetus). For some analyses an aliquot of the PCR reaction was size fractionated by electrophoresis in agarose gel, transferred onto nylon membranes, and hybridized with radiolabeled internal oligonucleotides as described previously (Hunger et al. 1991). Oligonucleotides employed included I5' (5'-GCCAGGGCATCTCAC-3'), I3' (5'GCACCAGAAATCTCAG-3'), INS-INT (5'-CAGAGGGACC- 
GGAGTCGGGC-3'), INS-DS (5'-GAAACTGCTGACCTGTGGGTCC-3'), and INS-US (5'-CTGGCCCTGTGCCTTCCACC3').

\section{Blot analyses}

Southern blot analyses of HAL-01 cell line DNA were performed on $10 \mu \mathrm{g}$ of DNA by use of an E2A-specific probe (E47M) under conditions described previously (Mellentin et al. 1989). Poly(A)-selected RNAs were purified from cell lines and tissues with commercial reagents (Invitrogen) under conditions recommended by the supplier. Adult human tissues were obtained from autopsy specimens, and human fetal tissues were obtained from a fetus of 18-22 weeks gestational age. All human tissue usage was approved by the human subjects committee of Stanford University. RNA was size-fractionated in denaturing formaldehyde $-0.8 \%$ agarose gels, transferred to nylon membranes, and hybridized under conditions described elsewhere (Cleary et al. 1986). Blots were washed under high-stringency conditions $\left(0.1 \times\right.$ SSC, $0.1 \%$ SDS at $\left.63^{\circ} \mathrm{C}\right)$ and exposed for $24-72 \mathrm{hr}$ at $-80^{\circ} \mathrm{C}$ with intensifying screens. The $H L F$ probe for Northern blot analyses consisted of an $\sim 1 \mathrm{~kb} S c a$ I fragment of $H L F$ cDNA containing the bZIP domain and a portion of the 3 - untranslated region. The $E 2 A$ probe used for Northern blots (probe $B$ ) is described above; a human $\gamma$-actin probe was used to ensure that adequate RNA had been isolated and equal amounts were loaded. A commercially prepared Northern blot (Clontech) was utilized for some analyses of adult tissues.

\section{Protein preparations}

Nuclear extracts of lymphoid leukemia cell lines were prepared as described previously (Kuo et al. 1991) with $1 \times 10^{7}$ to $2 \times 10^{7}$ logarithmically growing cells as starting material. Mobilityshift assays were performed with 3-5 $\mu$ g of nuclear protein. In vitro transcriptions were performed in a $100-\mu$ l volume by use of an in vitro transcription system (Promega) employing either $\mathrm{T} 7$ or SP6 polymerase and $2 \mu \mathrm{g}$ of appropriate linearized template DNA. In vitro translations were performed in a $25-\mu \mathrm{l}$ reaction containing $70 \%$ nuclease-treated rabbit reticulocyte lysate (Promega) and $0.5 \mu \mathrm{g}$ of in vitro-transcribed RNA under conditions recommended by the supplier. Mobility-shift assays were performed with $1-1.5 \mu \mathrm{l}$ of the in vitro translation reactions.

\section{DNA-binding studies}

Standard mobility-shift assays were performed as described previously (Drolet et al. 1991), with minor modifications. Gel shift oligonucleotides have been described previously for the growth hormone TEF site (Drolet et al. 1991), albumin D site (Mueller et al. 1990), and chicken VBP (Iyer et al. 1991). Binding reactions were performed at room temperature for $20 \mathrm{~min}$ in a $20-\mu \mathrm{l}$ volume of 20 mM HEPES (pH 7.8), 1 mM EDTA, 0.1\% NP-40, 15\% glycerol, $3 \mu \mathrm{g}$ of poly[d(I-C)], $0.5 \mu \mathrm{g}$ of bovine serum albumin, and $0.25 \%$ dry nonfat milk with $\sim 1 \mathrm{nM}$ double-stranded oligonucleotide. Oligonucleotide probes were labeled by fill-in with the Klenow fragment of DNA polymerase and ${ }^{32} \mathrm{P} \mid \mathrm{dCTP}$. Onefifth of each reaction was analyzed on a $5 \%$ nondenaturing $0.5 \times$ TBE-polyacrylamide gel, electrophoresed at $200 \mathrm{~V}$ for $2 \mathrm{hr}$. Autoradiography was performed on the dried gel for $6-18 \mathrm{hr}$ at $-80^{\circ} \mathrm{C}$. For supershift assays, binding reactions were performed as described above, followed by the addition of $1 \mu \mathrm{l}$ of appropriate serum and further incubation at $4^{\circ} \mathrm{C}$ for $16 \mathrm{hr}$. The anti-E2a antiserum has been described elsewhere (Murre et al. 1989).

\section{Computer analyses}

The University of Wisconsin Genetics Computer Group software package was used on a Digital Equipment VAX 8550 computer. Peptide sequences predicted from nucleotide analyses of the HLF cDNA were analyzed by use of the search algorithm FASTA at $k$ tup $=1$.

\section{Acknowledgments}

We thank members of the Cleary laboratory for helpful discussions, advice, and reagents, C. Kuo and J. Crabtree for reagents and advice, Linda Boxer for review of the manuscript, and J. Burch for Vbp reagents, discussion, and sharing unpublished data. We gratefully acknowledge D. Drolet and M.G. Rosenfeld for providing TEF reagents, U. Schibler for PCMV-DBP, and C. Murre for E2a antisera. Photographic support was provided by Phil Verzola and Judith Quenvold. This work was supported by grants from the National Institutes of Health (CA42971 and CA34233). S.P.H. was supported in part by a Physician's Research Training Fellowship (PRTF-00146) from the American Cancer Society; M.L.C. is a scholar of the Leukemia Society of America.

The publication costs of this article were defrayed in part by payment of page charges. This article must therefore be hereby marked "advertisement" in accordance with 18 USC section 1734 solely to indicate this fact.

\section{Note added in proof}

Sequence data described in this paper have been submitted to the EMBL/GenBank data libraries.

\section{References}

Agre, P., P.F. Johnson, and S.L. McKnight. 1989. Cognate DNA binding specificity retained after leucine zipper exchange be tween GCN4 and C/EBP. Science 246: 922-926.

Aplan, P.D., D.P. Lombardi, A.M. Ginsburg, I. Cossman, V.L. Bertness, and I.R. Kirsch. 1990. Disruption of the human SCL locus by "illegitimate" VID |J recombinase activity. Science 250: 1426-1429.

Brown, L., J.-T. Cheng, Q. Chen, M.J. Siciliano, W. Crist, G. Buchanan, and R. Baer. 1990. Site-specific recombination of the tal-1 gene is a common occurrence in human $\mathrm{T}$ cell leukemia. EMBO I. 9: 3343-3351.

Cleary, M.L. 1991. Oncogenic conversion of transcription factors by chromosomal translocations. Cell 66: 619-622.

Cleary, M.L., S.D. Smith, and J. Sklar. 1986. Cloning and structural analysis of cDNAs for $b c l-2$ and a hybrid $b c l-2 /$ immunoglobulin transcript resulting from the $t(14 ; 18)$ translocation. Cell 47: 19-28.

de Thé, H., C. Lavau, A. Marchio, C. Chomienne, L. Degos, and A. Dejean. 1991. The PML-RAR $\alpha$ fusion mRNA generated by the $(15 ; 17)$ translocation in acute promyelocytic leukemia encodes functionally altered RAR. Cell 66: 675-684.

Drolet, D.W., K.M. Scully, D.M. Simmons, M. Wegner, K. Chu, L.W. Swanson, and M.G. Rosenfeld. 1991. TEF, a transcription factor expressed specifically in the anterior pituitary during embryogenesis, defines a new class of leucine zipper proteins. Genes \& Dev. 5: 1739-1753.

Gentz, R., F.J. Rauscher III, C. Abate, and T. Curran. 1989. Parallel association of Fos and Jun leucine zippers juxtaposes DNA binding domains. Science 243: 1695-1699.

Henthorn, P., M. Kiledjian, and T. Kadesch. 1990. Two distinct 
transcription factors that bind the immunoglobulin enhancer $\mu \mathrm{E} 5 / \mathrm{kE} 2$ motif. Science 247: 467-470.

Hunger, S.P., N. Galili, A.J. Carroll, W.M. Crist, M.P. Link, and M.L. Cleary. 1991. The $t(1 ; 19)(q 23 ; p 13)$ results in consistent fusion of $E 2 A$ and $P B X 1$ coding sequences in acute lymphoblastic leukemias. Blood 77: 687-693.

Inaba, T., W.M. Roberts, K.W. Jolly, L.H. Shapiro, S.C. Raimondi, S.D. Smith, and A.T. Look. 1991. Molecular cloning of a $t(17 ; 19)(q 22 ; p 13)$ chromosomal translocation in lymphoblastic leukemia cells: The E2A gene on chromosome 19 is joined to new sequences on chromosome 17. Blood 78: 169 a (Abstr.).

Iyer, S.V., D.L. Davis, S.N. Seal, and J.B. Burch. 1991. Chicken vitellogenin gene-binding protein, a leucine zipper transcription factor that binds to an important control element in the chicken vitellogenin II promoter, is related to rat DBP. Mol. Cell. Biol. 11: 4863-4875.

Kakizuka, A., W.H. Miller Jr., K. Umesono, R.P. Warrell Jr., S.R. Frankel, V.V.V.S. Murty, E. Dmitrovsky, and R.M. Evans. 1991. Chromosomal translocation $t(15 ; 17)$ in acute promyelocytic leukemia fuses RAR $\alpha$ with a novel putative transcription factor, PML. Cell 66: 663-674.

Kamps, M.P., C. Murre, X.-H. Sun, and D. Baltimore. 1990. A new homeobox gene contributes the DNA binding domain of the $t(1 ; 19)$ translocation protein in pre-B ALL. Cell 60: $547-555$.

Kamps, M.P., A.T. Look, and D. Baltimore. 1991. The human $t(1 ; 19)$ translocation in pre-B ALL produces multiple nuclear E2A-Pbx 1 fusion proteins with differing transforming potentials. Genes \& Dev. 5: 358-368.

Kouzarides, T. and E. Ziff. 1988. The role of the leucine zipper in the fos-jun interaction. Nature 336: 646-651.

Kozak, M. 1987. An analysis of 5'-noncoding sequences from 699 vertebrate messenger RNAs. Nucleic Acids Res. 15: $8125-8138$.

Kuo, C.J., D.B. Mendel, L.P. Hansen, and G.R. Crabtree. 1991. Independent regulation of HNF- $1 \alpha$ and $H N F-1 \beta$ by retinoic acid in F9 teratocarcinoma cells. EMBO I. 10: 2231-2236.

Mellentin, J.D., C.M. Murre, T.A. Donlon, P.S. McCaw, S.D. Smith, A.J. Carroll, M.E. McDonald, D. Baltimore, and M.L. Cleary. 1989. The gene for enhancer binding proteins E12/ E47 lies at the $t(1 ; 19)$ breakpoint in acute leukemias. Science 246: 379-382.

Mellentin, J.D., J. Nourse, S.P. Hunger, S.D. Smith, and M.L. Cleary. 1990. Molecular analysis of the $t(1 ; 19)$ breakpoint cluster region in pre-B cell ALL. Genes Chromosomes Cancer 2: 239-247.

Metz, R. and E. Ziff. 1991. The helix-loop-helix protein rE12 and the C/EBP-related factor rNFIL- 6 bind to neighboring sites within the c-fos serum response element. Oncogene 6: 2165-2178.

Monica, K., N. Galili, J. Nourse, D. Saltman, and M.L. Cleary. 1991. PBX2 and $P B X 3$, new homeobox genes with extensive homology to the human proto-oncogene PBX1. Mol. Cell. Biol. 11: 6149-6157.

Mount, S.M. 1982. A catalouge of splice junction sequences. Nucleic Acids Res. 10: 459-471.

Mueller, C.R., P. Maire, and U. Schibler. 1990. DBP, a liverenriched transcriptional activator, is expressed late in ontogeny and its tissue specificity is determined posttranscriptionally. Cell 61: 279-291.

Murre, C., P.S. McCaw, and D. Baltimore. 1989. A new DNA binding and dimerization motif in immunoglobulin enhancer binding, daughterless, MyoD, and myc proteins. Cell 56: $777-783$.

Nourse, J., J.D. Mellentin, N. Galili, J. Wilkinson, E. Stanbridge,
S.D. Smith, and M.L. Cleary. 1990. Chromosomal translocation $t(1 ; 19)$ results in synthesis of a homeobox fusion mRNA that codes for a potential chimeric transcription factor. Cell 60: $535-545$.

Ohyashiki, K., H. Fujieda, J. Miyauchi, J.H. Ohyashiki, T. Tauchi, M. Saito, S. Nakazawa, K. Abe, K. Yamamoto, S.C. Clark, and K. Toyama. 1991. Establishment of a novel heterotransplantable acute lymphoblastic leukemia cell line with a $t(17 ; 19)$ chromosomal translocation the growth of which is inhibited by interleukin-3. Leukemia 5: 322-331.

Pandolfi, P.P., F. Grignani, M. Alcalay, A. Mencarelli, A. Biondi, F. LoCoco, F. Grignani, and P.G. Pelicci. 1991. Structure and origin of the acute promyelocytic leukemia myl/RARa CDNA and characterization of its retinoid binding and transactivation properties. Oncogene 6: 1285-1292.

Privitera, E., M.P. Kamps, Y. Hayashi, T. Inaba, L.H. Shapiro, S.C. Raimondi, F. Behm, L. Hendershot, A.J. Carroll, D. Baltimore, and A.T. Look. 1992. Different molecular consequences of the 1,19 chromosomal translocation in childhood B-cell precursor acute lymphoblastic leukemia. Blood 79: $1781-1788$.

Raimondi, S.C., E. Privitera, D.L. Williams, A.T. Look, F. Behm, G.K. Rivera, W.M. Crist, and C.-H. Pui. 1991. New recurring chromosomal translocations in childhood acute lymphoblastic leukemia. Blood 77: 2016-2022.

Turner, R. and R. Tiian. 1989. Leucine repeats and an adjacent DNA binding domain mediate the formation of functional cFos-cIun heterodimers. Science 243: 1689-1694.

Vinson, C.R., P.B. Sigler, and S.L. McKnight. 1989. Scissors-grip model for DNA recognition by a family of leucine zipper proteins. Science 246: 911-916.

Yamada, T., J.M. Craig, J.M. Hawkins, G. Janossy, and L.M. Secker-Walker. 1991. Molecular investigation of 19p13 in standard and variant translocations: The E12 probe recognizes the 19 p13 breakpoint in cases with $t(1 ; 19)$ and acute leukemia other than pre-B immunophenotype. Leukemia 5: $36-40$.

Zaret, K.S., J.-K. Liu, and C.M. Dipersio. 1990. Site-directed mutagenesis reveals a liver transcription factor essential for the albumin enhancer. Proc. Natl. Acad. Sci. 87: 5469-5473. 


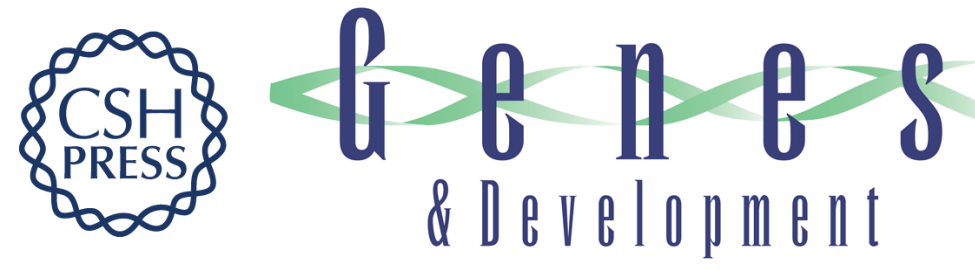

\section{HIf, a novel hepatic bZIP protein, shows altered DNA-binding properties following fusion to E2A in $t(17 ; 19)$ acute lymphoblastic leukemia.}

S P Hunger, K Ohyashiki, K Toyama, et al.

Genes Dev. 1992, 6:

Access the most recent version at doi:10.1101/gad.6.9.1608

References This article cites 34 articles, 15 of which can be accessed free at: http://genesdev.cshlp.org/content/6/9/1608.full.html\#ref-list-1

License

Email Alerting Service

Receive free email alerts when new articles cite this article - sign up in the box at the top right corner of the article or click here.

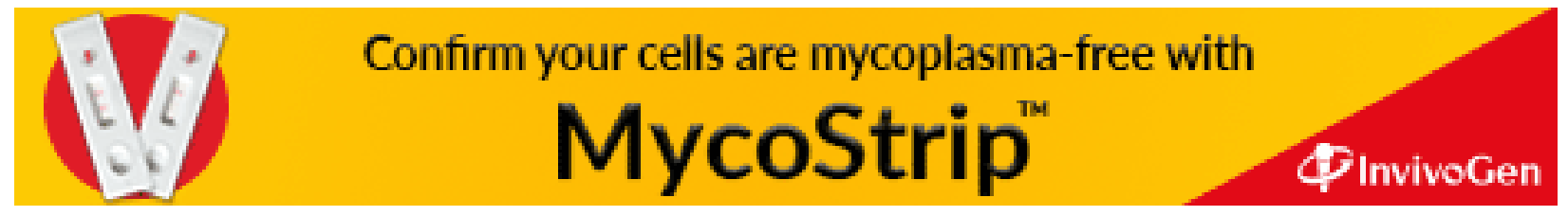

